\title{
A matched study of surgically treated stage IB adenosquamous carcinoma and adenocarcinoma of the uterine cervix
}

C.W. HELM*, W.K. KINNEY†, G. KEENEY†, W.D. LAWRENCE§, T.S. FRANK $\ddagger$, H. GORE*, R.K. REYNOLDS $\ddagger$, S-J. SOONG*, E.E. PARTRIDGE*, J. ROBERTS $\ddagger$ K. PODRATZt \& H.M. SHINGLETON*

*University of Alabama, Birmingham, Al 35294; +The Mayo Clinic, Rochester, MN 55905; łUniversity of Michigan, Ann Arbor, MI 48109; and §The Hutzel Hospital, Detroit, MI 48201, USA

\begin{abstract}
Helm CW, Kinney WK, Keeney G, Lawrence WD, Frank TS, Gore H, Reynolds RK, Soong S-J, Partridge EE, Roberts J, Podratz K, Shingleton HM. A matched study of surgically treated stage IB adenosquamous carcinoma and adenocarcinoma of the uterine cervix. Int J Gynecol Cancer 1993; 3: 245-249.

Thirty-eight patients with surgically treated stage IB adenosquamous carcinoma of the uterine cervix (AS) have been matched with patients with other histologic subtypes of adenocarcinoma (A) for stage, lesion size, node status, grade of adenocarcinoma and age at diagnosis. An additional six patients with AS were unable to be matched. Overall 5-year survival and disease-free survival for the matched AS and A were not significantly different, 83 vs. $90 \%$, and 78 vs. $81 \%$ nor were the number of recurrences, $8 / 38 \mathrm{AS}$ vs. $6 / 38 \mathrm{~A}$, but the mean time to recurrence was significantly shorter in the AS group: 11 vs. 32 months $(P=0.003)$. A subgroup of AS with a high risk of a poor outcome can be identified based on either lesion size $\geq 4 \mathrm{~cm}$, depth of invasion $\geq 10 \mathrm{~mm}$ or plevic lymph node metastasis. These patients may be suitable candidates for adjuvant therapy before or after surgical treatment.
\end{abstract}

KEYWORDS: adenocarcinoma, adenosquamous, carcinoma, cervix, prognosis, survival.

The significance of adenosquamous carcinoma (AS) as a separate sub-type of carcinoma of the cervix is still unclear. It is reported to represent approximately $30 \%$ of all adenocarcinomas of the cervix ${ }^{(1-19)}$ and up to $62 \%$ in individual series ${ }^{(6,7)}$. Papers have been published in support of both a poor prognosis for $\mathrm{AS}^{(1,4-7,13,14,20-23)}$ and a prognosis not significantly different from other types of adenocarcinoma (A) of squamous cell carcinoma $(\mathrm{SCC})^{(8-10,12,24)}$ (Table 1).

Address for correspondence: Dr C.W. Helm, Director, Division of Gynecologic Oncology, Department of Obstetrics and Gynecology, Temple University, Broad and Ontario Streets, Philadelphia, PA 19140, USA.
A major problem with the assessment of outcome for this tumor is that reports may include a variety of histologic types ranging from tumors composed of malignant squamous and glandular elements clearly identifiable with hematoxylin and eosin stains, to poorly differentiated SCC in which the glandular element is only revealed by the use of mucin stains. Despite the lack of agreement on the exact histologic criteria for AS many investigators do not even mention the actual criteria used in their studies ${ }^{(4,6,10,12,22)}$ which makes interpretation difficult.

Many reports of the outcome for AS are based on the experience of single institutions with relatively small numbers of patients who have been only clin- 
Table 1. Prognosis for adenosquamous carcinoma of the cervix

\begin{tabular}{|c|c|c|c|c|}
\hline Author & Year & $\begin{array}{l}\text { AS or 'mixed' } \\
\text { carcinoma }\end{array}$ & Prognosis & $\begin{array}{l}\text { Include SCC with } \\
\text { positive mucin }\end{array}$ \\
\hline Kilgore et al. ${ }^{(9)}$ & 1988 & 47 & Same as $A$ and SCC by stage & no \\
\hline Korhonen $^{(10)}$ & 1984 & 40 & Same as A overall & $*$ \\
\hline Rutledge et al..$^{(12)}$ & 1975 & 25 & Same as A overall & * \\
\hline Hopkinset al. ${ }^{(8)}$ & 1988 & 66 & Same as A overall and by stage & no \\
\hline Benda et al. ${ }^{(32)}$ & 1985 & 18 & Same as $\mathrm{A}$ and $\mathrm{SCC}$ & yes \\
\hline Abell \& Gosling ${ }^{(1)}$ & 1962 & 11 & Worse than $A$ and SCC & no \\
\hline Kottmeier ${ }^{(23)}$ & 1964 & 153 & Worse than A and SCC & yes \\
\hline Swan \& Roddick ${ }^{(14)}$ & 1973 & 20 & Worse than A and SCC & yes \\
\hline Davidsonet al..$^{(4)}$ & 1989 & 21 & Worse than A and SCC & * \\
\hline Gallupetal..$^{(6)}$ & 1985 & 20 & Worse than A and SCC overall and IB & * \\
\hline Fuetal. ${ }^{(5)}$ & 1982 & 37 & Worse than A overall and by stage & * \\
\hline Glucksmann \& Cherry $^{(7)}$ & 1956 & 195 & Worse than SCC & yes \\
\hline Saigo et al..$^{(13)}$ & 1986 & 20 & Worse than endometrioid $\mathrm{A}$ & no \\
\hline Wheeless et al. ${ }^{(20)}$ & 1970 & 58 & Worse than SCC & yes \\
\hline Julian et al. ${ }^{(21)}$ & 1977 & 26 & Worse than SCC & * \\
\hline Adcock et al. & 1982 & 26 & Worse than SCC & * \\
\hline Ireland et al. ${ }^{(36)}$ & 1985 & 18 & Worse than SCC & yes \\
\hline
\end{tabular}

* = not mentioned.

ically staged. To date, 14 publications have reported an average of 19 stage I or IB AS tumors per study $^{(4-7,9,11,13,15,21-23,25,26)}$. Only six papers have reported on surgically staged I or IB patients with an average of only 10 cases per study ${ }^{(6,9,21,22,25,26)}$ and surgical staging is critical for precise clinico-pathologic investigation.

This study was designed to investigate the outcome of a relatively large number of patients with stage IB, histologically confirmed, AS in whom the exact extent of disease had been surgically determined in comparison with a group of patients with surgically treated adenocarcinomas of other histologic subtypes matched for lesion size, pelvic lymph node status, grade of adenocarcinoma and age.

\section{Materials and methods}

Patients with clinical stage IB adenosquamous carcinoma of the cervix were identified from the tumor registries of the University of Alabama at Birmingham, The University of Michigan, Ann Arbor and the Mayo Clinic, Rochester. Clinical data were obtained from the individual medical records and where appropriate by direct patient contact. The strict criteria for entry into the study for both adenosquamous and adenocarcinomas were: (i) disease surgically confirmed to be confined to the uterine cervix with or without lymph node metastasis; (ii) lymph node status confirmed by pelvic lymphadenectomy; (iii) complete medical rec- ords and pathologic material; (iv) histologic confirmation. The patients with AS were matched with $A$ for the following criteria: lesion size (greatest diameter in $\mathrm{cm}$ ), pelvic lymph node status, architectural grade of the adenocarcinoma and age at diagnosis. The intention was to match patients treated within the same center where possible. Lesion size was matched to within $0.5 \mathrm{~cm}$ below $4 \mathrm{~cm}$ and to within $1 \mathrm{~cm}$ above 4 $\mathrm{cm}$. Pelvic nodes were matched by positive and negative and by number if positive, grade \pm 1 , and age as closely as possible. Histology review was performed by three histopathologists (WDL, TSF, GK) sitting together. As part of a complete review of all AS carcinoma of the cervix treated at the three institutions agreed histologic criteria were established for the diagnosis of AS as "a tumor which contains obvious malignant glandular and squamous elements using conventional hematoxylin and eosin-staining. Glandular elements are recognized by overt gland formation or by the presence of 'signet ring' cells. Squamous differentiation, as in pure squamous carcinoma of the cervix, is characterized by either frank keratinization or by nests of spindle cells or large cells with intercellular bridges". Glassy cell carcinoma is considered to be an adenosquamous variant and eligible patients were included in the study. Glassy cell carcinoma was characterized as described by Glücksman \& Cherry ${ }^{(7)}$ by the presence of "large cells containing a moderate amount of finely granular cytoplasm, which gives them their characteristic ground-glass appearance. The 
cytoplasm stains faintly blue with hematoxylin. The cells have a distinct cell wall, and the nuclei are prominent and contain prominent nucleoli". No special stains were included in the criteria. Only patients with definite carcinoma of the uterine cervix were included. The definition of adenocarcinoma included all other recognized forms of adenocarcinoma as described by Blaustein $^{(27)}$, including columnar cell (endocervical), colloid, endometrioid, papillary serous and clear cell, adenoid cystic and mesonephric sub-types.

In the adenocarcinomatous elements grading was based on the architectural pattern: a well-differentiated tumor contained well-formed simple glands, moderately differentiated was characterized by interbranching glands and variable amounts of intracytoplasmic mucin which may show a cribriform pattern and a poorly differentiated contained sheets of cells with only focal gland formation. A well-differentiated squamous cell carcinoma was characterized by mature cells with abundant eosinophilic cytoplasm with or without abundant keratin with keratin pearls and individual cell keratinization (dyskeratosis). Cells were usually tightly packed together with well-developed intercellular bridges. Moderately well-differentiated neoplastic cells were more pleomorphic with large irregular nuclei, less abundant cytoplasmic matrix and more numerous mitotic figures. The cellular borders as well as intercellular bridges were indistinct. Keratin pearl formation was virtually non-existent and individual cell keratinization present in the center of nests of tumor cells.

Poorly differentiated tumors contained abundant mitoses and areas of necrosis. The cells contained hyperchromatic oval nuclei and scant indistinct cytoplasm. There were rare foci of abortive dyskeratosis only. Depth of invasion was measured as the thickness of the tumor in a plane perpendicular to the adjacent epithelium.

Statistical analysis was performed in the Division of Biostatistics, Comprehensive Cancer Center, University of Alabama at Birmingham. Survival curves were calculated according to the method of Kaplan and Meier with differences compared using the log rank test. The $t$-tests and Chi-square tests were used as appropriate.

\section{Results}

Ninety-two patients were initially thought to be eligible for inclusion but 48 patients were excluded because they did not meet the strict entry criteria for the following reasons: histology not adenosquamous on review ( $n=32)$, incomplete clinical data $(n=3)$, insufficient histologic material $(n=10)$ and surgical stage
Table 2. Details of matching data

\begin{tabular}{lrr}
\hline & AS & Adenocarcinoma \\
\hline & $n=38$ & $n=38$ \\
Lesion size & 11 & 12 \\
$1-1.9$ & 9 & 8 \\
$2-2.9$ & 10 & 10 \\
$3-3.9$ & 8 & 8 \\
$\geq 4$ cm & & \\
Pelvic lymph node status & 34 & 34 \\
0 & 3 & 2 \\
1 & 1 & 2 \\
2 & & \\
Grade & 3 & 9 \\
Well & 22 & 8 \\
Moderate & 13 & \\
Poor & & 3 \\
Age & 7 & 11 \\
$20-29$ & 10 & 15 \\
$30-39$ & 16 & 9 \\
$40-49$ & 5 & \\
$\geq 50$ & & \\
\hline
\end{tabular}

other than IB $(n=4)$. These four patients had tumor extension outside the cervix, vagina (1), parametrium (2), paracervical tissues (1). Additionally, two patients initially thought to be stage IB adenocarcinoma but found on histology review to be AS had disease extension outside the cervix at surgery into the parametrium (1) and vagina (1).

Forty-four patients met the entry criteria. It was not possible to match six AS patients. Five of these patients had positive lymph nodes in association with a lesion size between 2 and $4 \mathrm{~cm}$ and one had a lesion size of $8 \mathrm{~cm}$ with negative nodes. One patient in the AS group had a glassy cell tumor and another had glassy cell elements. Thirty-eight patients with AS were matched one-for-one with 38 patients with $A$ by the study criteria (Table 2). The average age of the matched AS and A groups was 41 years (range 22-63 years) and 43 years (range 26-73 years). Complete pelvic lymphadenectomy was performed in 36 patients in each group with sampling of the pelvic nodes in two cases each. Sampling of the paraaortic nodes was performed in $15 \mathrm{AS}$ and $12 \mathrm{~A}$ and all were negative for metastasis. Peritoneal washings were examined cytologically in $19 \mathrm{AS}$ and $14 \mathrm{~A}$ and in all cases were negative for malignant cells.

All 38 patients with AS underwent radical hysterectomy with five receiving postoperative radiotherapy. In the A group, 35 patients underwent radical hysterectomy with four receiving postoperative RT. Three A patients underwent total abdominal hysterectomy and staging laparatomy one following preoperative 


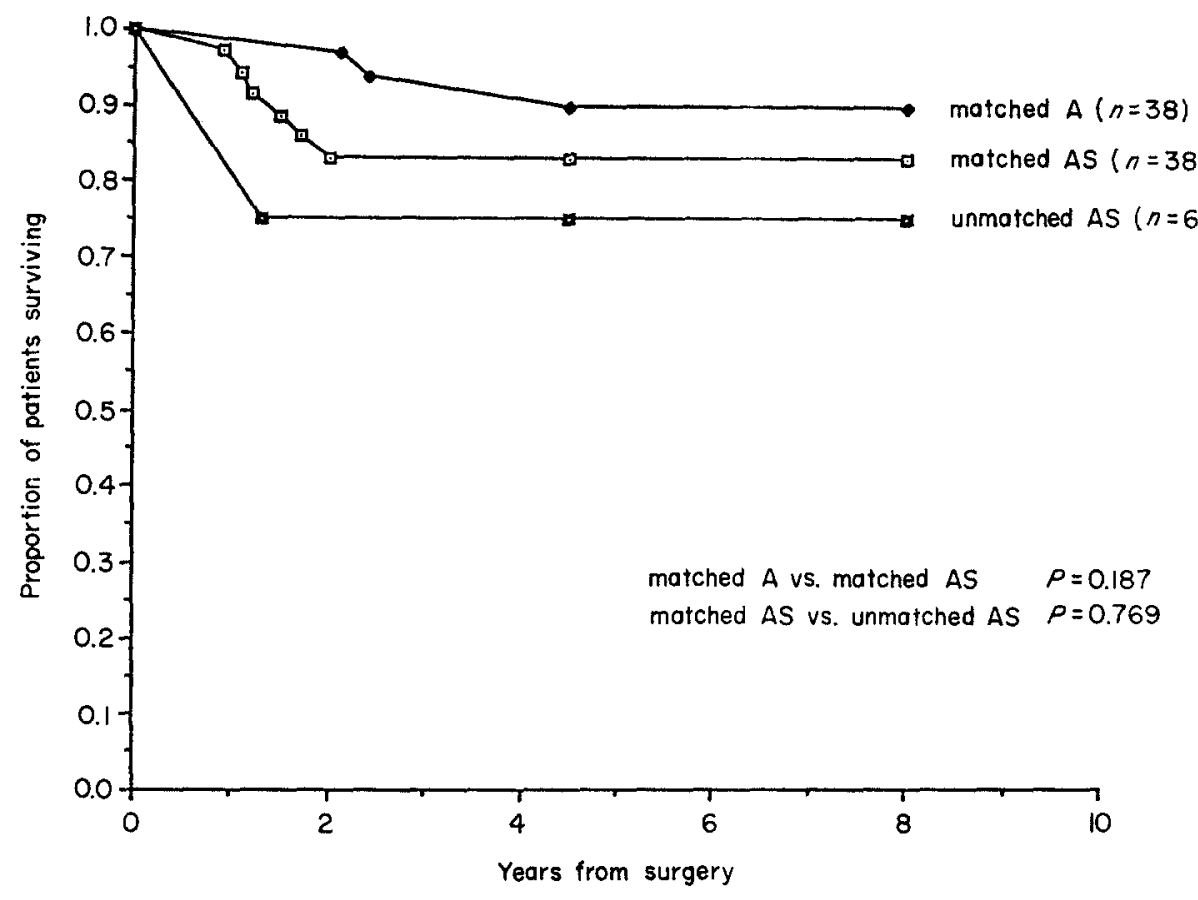

Fig. 1. Survival for matched AS and A and unmatched AS.

RT. All three underwent postoperative RT. The matched group of adenocarcinomas included the following subtypes: endocervical (33), colloid (2), papillary (1), endometrioid (1) and adenoid cystic (1).

The 5-year survival for the 38 matched AS patients was 83 vs. $90 \%$ for the A $(P=0.275$ for comparison of the two survival curves, Fig. 1). For the 34 patients in each group with negative nodes the 5-year survival was $84 \%$ AS and $93 \%$ A $(P=0.225)$. Of the four matched AS patients with positive nodes one is dead of disease, one is lost to follow-up after experiencing a vaginal vault recurrence and two are alive and well at 126 and 106 months. Of the four matched $A$ with positive nodes one is dead of disease, one is dead of another cause, one is alive with recurrence and one is alive and free of disease at 62 months. The overall disease-free survival was not significantly different between the matched groups $78 \%$ AS: $81 \%$ A $(P=0.522$ for the comparison of the two disease-free survival curves, Fig. 2) but the average time to recurrence was significantly shorter for the AS patients, 11 vs. 36 months $(P=0.03)$.

Eight $(25 \%)$ patients in the matched AS group recurred, four in the pelvis alone, three pelvis and distant, and one distant only. Six of the eight patients who recurred died of carcinoma of the cervix. Two other patients had recurrence in the vaginal vault, one surviving after treatment and the other lost to followup before treatment. Six of the matched A recurred with the sites being pelvis alone (2), pelvis and distant (1) and distant (3).

No patient with either AS or A recurred or died following treatment for the primary tumor with a depth of invasion $<1.0 \mathrm{~cm}$ (Fig. 3). In the matched AS group 8 of $15(53 \%)$ patients with depth of invasion $\geq 1 \mathrm{~cm}$ recurred as opposed to 6 of $15 \mathrm{~A}(40 \%)$. Of these $15 \mathrm{~A}$ patients four had positive nodes and three recurred and three of 11 with negative nodes recurred. When all the AS are examined 10 of $20(50 \%)$ with depth of invasion $\geq 1 \mathrm{~cm}$ recurred, six of the 20 had positive nodes and four recurred whilst six of 14 with negative nodes recurred.

In the matched study no AS or A patients were pregnant at the time of diagnosis but two of the unmatched AS patients were pregnant at 28 and 35 weeks and both were treated with Caesarean hysterectomy and postoperative radiotherapy. One of these patients had two positive pelvic nodes and is alive without recurrence at 130 months and the other with one positive node is dead of disease at 8 months.

Survival was significantly better for those matched AS with lesion size $<2 \mathrm{~cm}$ when compared with those $\geq 4 \mathrm{~cm}(P=0.025)$. The 44 patients with AS (including the unmatched patients) were divided into 


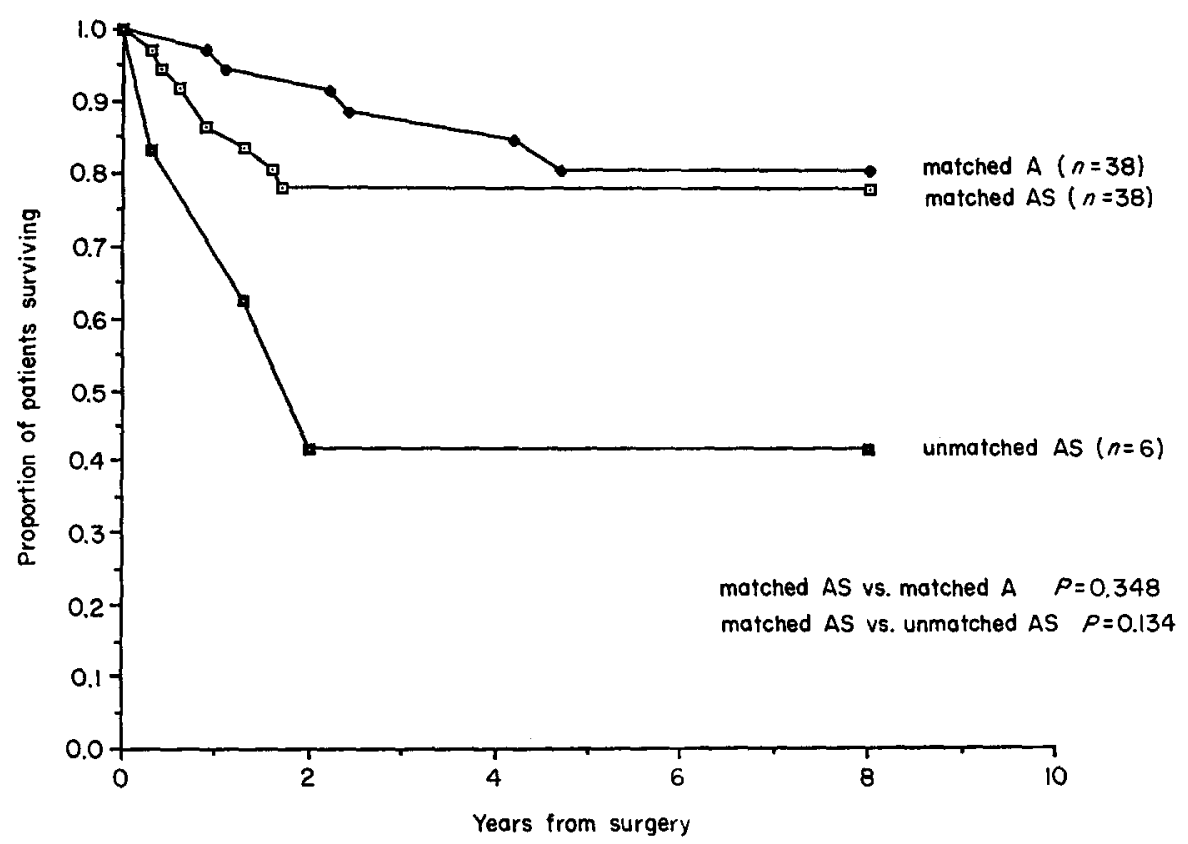

Fig. 2. Disease-free survival for matched $A$ and As and unmatched AS.

two groups based on node positivity, lesion size $\geq 4$ $\mathrm{cm}$ or depth of invasion $\geq 1 \mathrm{~cm}$ and anlysis revealed 25 AS patients with a significantly higher risk for recurrence (Fig. 4).

\section{Discussion}

Debate about the significance of adenosquamous carcinoma of the cervix has been dogged by a failure of researchers to adhere to either a uniform name or uniform histologic criteria for the tumor. At least five different terms have been applied to describe tumors containing both squamous and glandular elements including pseudo-epidermoid ${ }^{(28)}$, mixed carcinoma ${ }^{(7)}$, mucoepidermoid $^{(29)}$, acantho-adenocarcinoma ${ }^{(1)}$, adenoepidermoid $^{(20)}$ and adenosquamous ${ }^{(21)}$.

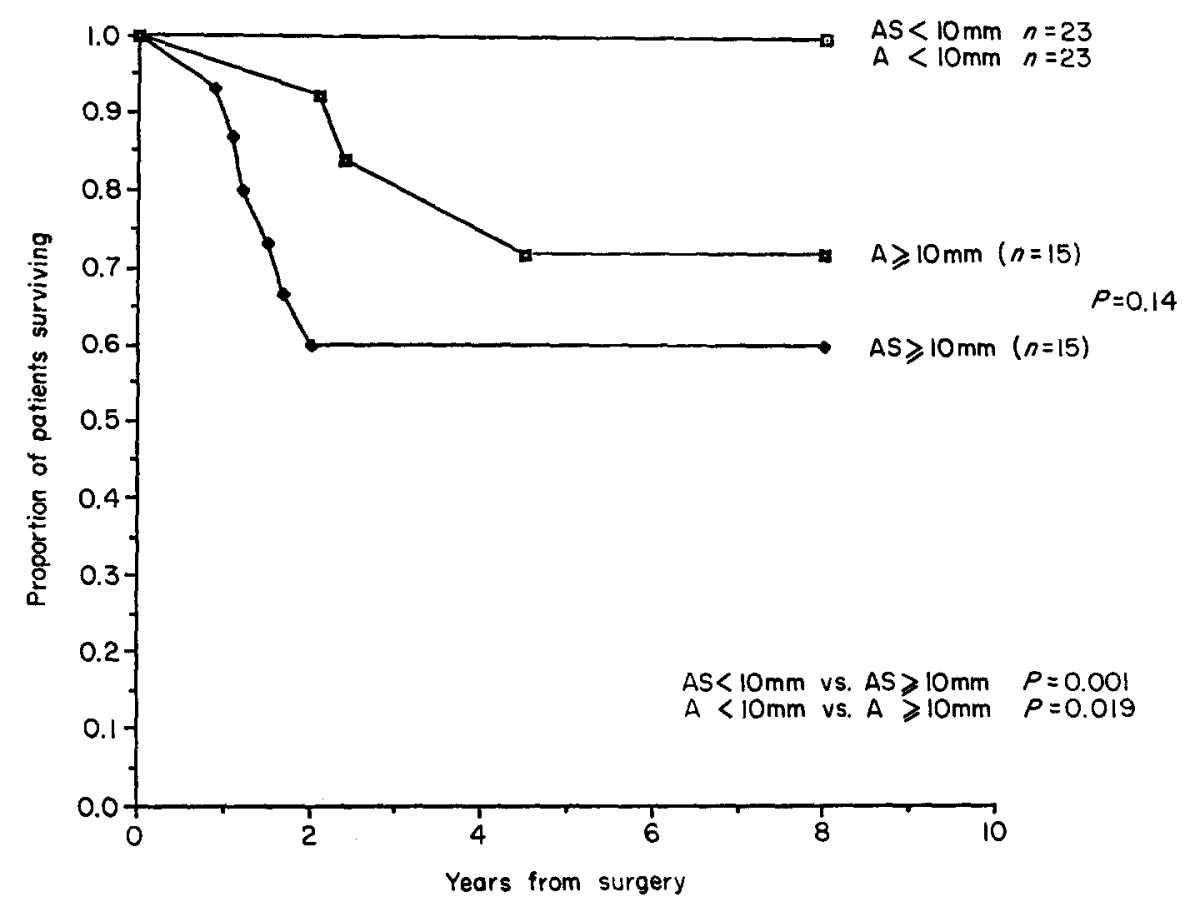

Fig. 3. Survival by depth of invasion-matched patients. 


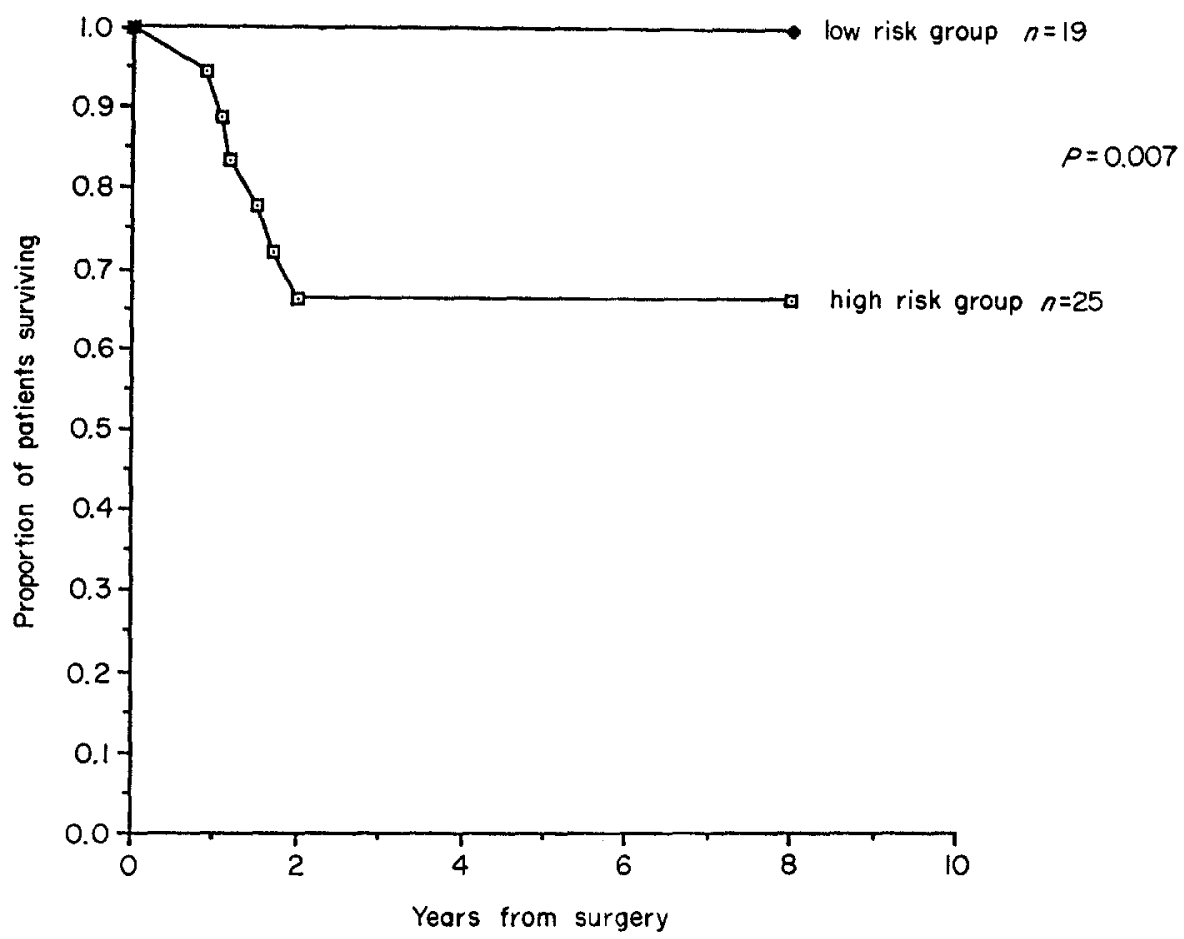

Fig. 4. Survival for high and low risk AS.

Table 3. Significant factors not included in matching

\begin{tabular}{lrr}
\hline & AS & Adenocarcinoma \\
\hline Depth of invasion & & \\
$<2.9 \mathrm{~mm}$ & 0 & 3 \\
$3-6.9$ & 10 & 16 \\
$7-9.9 \mathrm{~mm}$ & 12 & 3 \\
$10-19.9 \mathrm{~mm}$ & 12 & 11 \\
$\geq 20 \mathrm{~mm}$ & 3 & 4 \\
Unknown & 1 & 1 \\
Overall grade & & \\
Well & 1 & 9 \\
Moderate & 18 & 21 \\
Poor & 19 & 8 \\
\hline
\end{tabular}

The main area of contention is whether or not to include tumors which do not contain obvious squamous and glandular elements on conventional hematoxylin and eosin (H\&E) stains but which contain areas or cells which stain positive for mucin with special stains. It has been reported that such tumors have a worse prognosis, or worse prognostic features, than pure squamous cell carcinomas with no mucin positive cells $^{(23,30,31)}$ although others report no significant difference in survival ${ }^{(32)}$. Some investigators include such patients in series of adenosquamous carcinomas ${ }^{(7,14,20)}$ and report a worse outcome over either pure $\operatorname{SCC}^{(7,20)}$ or other forms of $\mathrm{A}$ and $\mathrm{SCC}^{(14)}$ (Table 1). The inclusion of patients with squamous cell carcinoma and mucin staining produces an uncertainty with regard to the actual amount of mucin staining required to change the classification of an $\mathrm{SCC}^{(29,30)}$ and makes interpretation difficult.

We decided to restrict the histologic criteria to those features which are readily definable by routine $H \& E$ staining without resort to special stains in order to obtain a homogeneous group for study. The difficulties associated with the diagnosis of AS carcinoma are exemplified by the fact that $32(35 \%)$ patients originally diagnosed with AS were excluded from the study because on review of the histology they were considered not to have AS at all. Seventeen were reclassified as adenocarcinomas, 14 as SCC and one as an adenoid basal carcinoma. Despite these exclusions, this is the largest series of surgically staged IB adenosquamous carcinoma of the cervix so far reported.

The process of matching patients with those with adenocarcinoma of other histologic types allows for a stricter comparison of both prognosis and prognostic features than would otherwise be possible. The matching criteria were selected because the features had been previously shown to be significant with regard to prognosis of either carcinoma of the cervix in general, adenocarcinoma or AS; lesion size ${ }^{(13,15,18,33-35)}$, lymph 
node status $^{(9,24,36,37)}$, tumor $\operatorname{grade}^{(5,8-10,15,18,35,36,38,39)}$ and age $\mathrm{e}^{(9,40)}$.

Our patients with AS carcinoma stage IB did have a worse survival than the matched group of other types of A ( 83 vs. $90 \%$ ) but the difference was not significantly different overall. However, other factors indicate that a sub-group of AS tumors do have a more aggressive tendency. The disease-free interval, a measure of the time to first recurrence, was significantly shorter in the AS group; the fact that five patients with metastases to pelvic lymph nodes in association with relatively small lesion size could not be matched with adenocarcinomas; a higher incidence of poor grade either of the adenocarcinoma component or overall and the greater incidence of patients under 30 years of age. Depth of invasion of the primary tumor was not included in our matching criteria but has been reported to be associated with a worse outcome in adenocarcinoma $a^{(2,13,24,25)}$ and our data would agree with this view.

In summary, our data demonstrate that early stage adenosquamous carcinoma of the cervix affords the patient a likelihood of survival not significantly different from an adenocarcinoma of similar size and extent of spread. However, the fundamental differences in tumor biology between these two cell types are manifested in the markedly shorter time to recurrence observed in adenosquamous patients, and in the propensity for nodal metastasis of adenosquamous cancers of smaller size which prevented matching of three out of eight of the node positive adenosquamous tumors with a greatest dimension of $\leq 4 \mathrm{~cm}$.

The data also indicate that a distinct sub-group of AS carcinoma can be identified based on either lesion size $\geq 4 \mathrm{~cm}$, depth of invasion $\geq 10 \mathrm{~mm}$ or node positivity who are at a much higher risk of early recurrence and poor survival. We feel that consideration should be given to some form of adjuvant chemoradiation before or after primary surgery for this group.

\section{Conclusion}

There is a sub-group of AS who have a more aggressive tumor with a shorter time to recurrence and poorer prognosis than matched adenocarcinomas. This group includes patients with positive pelvic lymph nodes, lesion size $\geq 4 \mathrm{~cm}$ and depth of invasion into the cervix of $\geq 10 \mathrm{~mm}$. Consideration should be given to adjuvant chemo-irradiation for this group. Conversely, a group of patients with AS who have a good prognosis can be identified by surgical staging.

\section{Acknowledgements}

This paper would not have been possible without the willing and able assistance of Ms Cindy Pouliot, Ms Kay Kuykendall, Ms Bonnie Gallup, Ms C Helm and the staff of the Biostatistics Unit, Comprehensive Cancer Center, University of Alabama at Birmingham.

\section{References}

1 Abell MR, Gostling JRG. Gland cell carcinoma (adenocarcinoma) of the uterine cervix. Am J Obstet Gynecol 1962; 83: 729-55.

2 Berek JS, Hacker NF, Fu Y-S, Sokale JR, Leuchter RC, Lagasse LD. Adenocarcinoma of the uterine cervix: histologic variables associated with lymph node metastasis and survival. Obstet Gynecol 1985; 65: 46-52.

3 Brinton LA, Tashima KT, Lehman HF, et al. Epidemiology of cervical cancer by cell type. Cancer Res 1987; 47: 1706-11.

4 Davidson SE, Symonds RP, Lamont D, Watson ER. Does adenocarcinoma of uterine cervix have a worse prognosis than squamous carcinoma when treated by radiotherapy? Gynecol Oncol 1989; 33: 23-6.

5 Fu YS, Reagan JW, Hsiu JG, Storaasli JP, Wentz WB. Adenocarcinoma and mixed carcinoma of the uterine cervix. Cancer 1982; 49: 2560-70.

6 Gallup DG, Harper RH, Stock RJ. Poor prognosis in patients with adenosquamous cell carcinoma of the cervix. Obstet Gynecol 1985; 65: 416-22.

7 Glücksmann A, Cherry CP. Incidence histology and response to radiation of mixed carcinomas (adenocanthomas) of the uterine cervix. Cancer 1956; 9: 971-9.

8 Hopkins MP, Schmidt RW, Roberts JA, Morley GW. Gland cell carcinoma (adenocarcinoma) of the cervix. Obstet Gynecol 1988; 72: 789-95.

9 Kilgore LC, Soong S-J, Gore H, Shingleton HM, Hatch KD, Partridge EE. Analysis of prognostic features in adenocarcinoma of the cervix. Gynecol Oncol 1988; 31: 137-48.

10 Korhonen MO. Adencarcinoma of the uterine cervix. Cancer 1984; 53: 1760-3.

11 Randall ME, Kim J, Mills SE, Hahn SS, Constable WC. Uncommon variants of cervical carcinoma treated with radical irradiation. Cancer 1986; 57: 816-22.

12 Rutledge FN, Galakatos AE, Wharton JT, Smith JP. Adenocarcinoma of the uterine cervix. Am J Obstet Gynecol 1975; 122: 236-45.

13 Saigo PE, Cain JM, Kim WS, Gaynor JJ, Johnson K, Lewis JL. Prognostic factors in adenocarcinoma of the uterine cervix. Cancer 1986; 57: 1584-93.

14 Swan DS, Roddick JW. A clinical-pathological correlation of cell type classification for cervical cancer. Am J Obstet Gynecol 1973; 116: 666-70.

15 Tamimi HK, Figge DC. Adenocarcinoma of the uterine cervix. Gynecol Oncol 1982; 13: 335-44.

16 Tasker JT, Collins JA. Adenocarcinoma of the uterine cervix. Am J Obstet Gynecol 1974; 118: 344-8.

17 Weiner S, Wizenburg MJ. Treatment of Primary Adenocarcinoma of the cervix. Cancer 1975: 35: 1514-16.

18 Weiss RJ, Lucas WE. Adenocarcinoma of the uterine cervix. Cancer 1986; 57: 1996-2001. 
19 Mikuta JJ, Celebre JA. Adenocarcinoma of the cervix. Obstet Gynecol 1969; 33: 753-6.

20 Wheeless CR, Jr, Graham R, Graham JB. Prognosis and treatment of adenoepidermoid carcinoma of the cervix. Obstet Gynecol 1970; 35: 928-32.

21 Julian CG, Daikoku NH, Gillespie A. Adenoepidermoid and adenosquamous carcinoma of the uterus. Obstet Gynecol 1977; 128: 106-17.

22 Adcock LL, Julian TM, Okagaki T, et al. Carcinoma of the uterine cervix FIGO stage I-B. Gynecol Oncol 1982; 14: 199-208.

23 Kottmeier HL. Surgical and radiation treatment of carcinoma of the uterine cervix. Acta Obstet Gynecol Scand 1964; 43 (suppl. 2) 1-48.

24 Hopkins MP, Schmidt RW, Roberts JA, Morley GW. The prognosis and treatment of stage 1 adenocarcinoma of the cervix. Obstet Gynecol 1988; 72: 915-21.

25 Greer BE, Figge DC, Tamimi HK, Cain JM. Stage 1B adenocarcinoma of the cervix treated by radical hysterectomy and pelvic lymph node dissection. Am J Obstet Gynecol 1989; 160: 1509-14.

26 Lagasse LD, Creasman WT, Shingleton HM, Ford JH, Blessing JA. Results and complications of operative staging in cervical cancer: experience of the Gynecological Oncology Group. Gynecol Oncol 1980; 9: 90-8.

27 Ferenczy A. Malignant neoplasms of the uterine cervix. In: Kurman RJ, ed. Blanstein's Pathology of the Female Genital Tract. New York: Springer Verlag, 1987: 237-40.

28 Regaud C, Gricouroff G. Sur la classification histogenetique des epitheliomas cervico-uterins, et particulierement sur les epitheliomas pseudo-epidermiques, originaires de l'epithelium canalaire mucipare. Bull Ass franc Cancer 1933; 22: 285-96.

29 Hellweg G. Uber schleimbildung in plattenepithelcarcinomen, insbesondere an der portio uteri (mucoepidermoid carcinome). Z Krebsforsch 1957; 61: 688-715.
30 Buckley $\mathrm{CH}$, Beards CS, Fox $\mathrm{H}$. Pathological prognostic indicators in cervical cancer with particular reference to patients under the age of 40 years. Obstet Gynecol 1988; 95: 47-56.

31 Ireland D, Cole S, Kelly P, Monaghan JM. Mucin production in cervical intraepithelial neoplasia and stage $1 \mathrm{~B}$ carcinoma of the cervix with pelvic lymph node metastases. Obstet Gynecol 1987; 94: 467-72.

32 Benda JA, Platz CE, Buchsbaum H, Lifshitz S. Mucin production in defining mixed carcinoma of the uterine cervix: a clinicopathologic study. Int J Gynecol Path 1985; 4: 314-27.

33 Piver MS, Chung WS. Prognostic significance of cervical lesion size and pelvic node metastases in cervical carcinoma. Obstet Gynecol 1975; 46: 507-10.

34 Grigsby PW, Perez CA, Kuske RR, Camel HM, Kao MS, Galakatos AE, Hederman MA. Adenocarcinoma of the uterine cervix: Lack of evidence for a poor prognosis. Rad Oncol 1988; 12: 289-96.

35 Prempree T, Amornmarn R, Wizenberg MJ. A therapeutic approach to primary adenocarcinoma of the cervix. Cancer 1985; 56: 1264-8.

36 Ireland D, Hardiman P, Monaghan JM. Adenocarcinoma of the uterine cervix: a study of 73 cases. Obstet Gynecol 1985; 65: 82-5.

37 Kjorstad KE, Bond B. Stage 1B adenocarcinoma of the cervix: metastatic potential and patterns of dissemination. Am J Obstet Gynecol 1984; 150: 297-9.

38 Shingleton HM, Gore H, Bradley DH, Soong S-J. Adenocarcinoma of the cervix. Am J Obstet Gynecol 1981; 139: 799-814.

39 Berek JS, Castaldo TW, Hacker NF, Petrilli ES, Lagasse LD, Moore JG. Adenocarcinoma of the uterine cervix. Cancer 1981; 48: 2734-41.

40 Murrell DS, Helm CW, Bourne H. Carcinoma of the cervix in women up to 35 years of age. Clin Oncol 1990; 2: 260-3.

Accepted for publication 19 August 1992 